\section{Ammonium ylides for the diastereoselective synthesis of glycidic amides $\nmid$}

\author{
Mario Waser,* Richard Herchl and Norbert Müller \\ Received 5th November 2010, Accepted 30th November 2010 \\ DOI: $10.1039 / \mathrm{c0cc04821f}$
}

\begin{abstract}
A highly trans-selective protocol for the synthesis of glycidic amides was developed. This approach gave access to oxiranes by reacting stabilised ammonium ylides bearing an $\alpha$-carbonyl group and aromatic aldehydes in moderate to good yields.
\end{abstract}

The (dia-)stereoselective synthesis of glycidic amides and esters has attracted considerable interest over the last few decades mainly due to the high potential of these compounds as synthetically useful intermediates in a variety of organic syntheses. Ylides have proven to be very powerful synthons for the formation of epoxides ${ }^{1-4}$ providing alternatives to the oxidation of $\alpha, \beta$-unsaturated carbonyl compounds ${ }^{5,6}$ or the Darzens reaction between $\alpha$-halo esters or amides and carbonyl groups. ${ }^{7}$ The synthesis of oxirane rings by reacting a sulfur ylide with an aldehyde or ketone was introduced around 50 years ago $^{1}$ and a variety of applications using chiral sulfonium ylides either in stoichiometric or even in catalytic quantities have been reported. ${ }^{2-4}$ Next to sulfur ylides the use of ammonium ylides for $\mathrm{C}-\mathrm{C}$ bond formation has attracted considerable interest over the last few years. ${ }^{8-14}$ Gaunt et al. showed that cinchona alkaloid catalysts are highly useful for stereoselective cyclopropanations proceeding via an ammonium ylide mechanism. ${ }^{8}$ Besides the syntheses of cyclopropanes the diastereoselective formation of epoxides in analogy to the Corey-Chaykovsky reaction has been described. ${ }^{11-13}$ However, this synthetically useful transformation has so far been limited to benzylic ammonium ylides ${ }^{13}$ and cyano-stabilised ammonium ylides ${ }^{11,12}$ giving the corresponding oxiranes in moderate yields only, whereas ester-stabilised ylides did not yield the epoxides. ${ }^{14}$ Previous studies by Aggarwal et al. clearly showed that a key factor in ylide based epoxide formation reactions is the leaving group quality of the onium group, which decreases in the order $\mathrm{O}>\mathrm{S}>\mathrm{N}>\mathrm{P}$. 9 Furthermore, the presence of a carbonyl group $\alpha$ to the leaving group (stabilised ylides) significantly increases the barrier to ring closure. Altogether, these investigations clearly demonstrate why ammonium ylides are less suited for epoxide formation than sulfur ylides and rationalize why no oxirane

Institute of Organic Chemistry, Johannes Kepler University Linz,

Altenbergerstraße 69, 4040 Linz, Austria.

E-mail: Mario.waser@jku.at; Fax: +43732 2468 8747;

Tel: +4373224688748

$\dagger$ Electronic supplementary information (ESI) available: Experimental part including analytical and spectroscopic data of all new compounds. See DOI: $10.1039 / \mathrm{c} 0 \mathrm{cc} 04821 \mathrm{f}$ syntheses with ammonium ylides bearing an $\alpha$-carbonyl group have been reported so far. ${ }^{9}$

However, from the few reported examples it was clearly proven by Jonczyk et al. ${ }^{11}$ that cyano-stabilised ylides (being less stabilised than esters) ${ }^{15}$ undergo such reactions under biphasic conditions in moderate yield. Furthermore, less stabilised benzylic ylides give access to trans-selective formation of stilbene oxides in moderate to good yields. ${ }^{13}$ Thus, it seems reasonable that similarly stabilised ammonium ylides might be successfully employed for epoxide formation.

Based on a recent investigation of the stability of ylides, ${ }^{15}$ we reasoned that amide based ammonium ylides (being less stabilised than cyano-based ylides, but higher stabilised than benzylic), might undergo oxirane formation when reacted with aldehydes since they should be sufficiently balanced with respect to nucleophilicity and leaving group ability. Due to the high interest in glycidic amides,${ }^{4}$ an ammonium ylide based synthetic approach would thus significantly broaden the scope of this methodology.

We therefore focused on the development of reactions between DABCO-derived amide-based ammonium ylides and aromatic aldehydes (Scheme 1).

Initial attempts were carried out reacting a small excess of benzaldehyde (1) with the diethylamide-derived ammonium salt 2 in dry THF using $t$-BuOK (1.2 equiv.) as the base at room temperature (Table 1, entry 1). After $24 \mathrm{~h}$, full conversion of 1 was observed and the trans-configured glycidic amide 3 could be isolated in $32 \%$ yield. Noteworthy, not even trace amounts of the cis-diastereomer were obtained (judged by ${ }^{1} \mathrm{H}$ NMR). As we had observed a significant decrease in yield $(<20 \%)$ using lower quality THF, addition of molecular sieves ( $4 \AA$ ) to the reaction mixture was tested, resulting in an improved yield of $47 \%$ (entry 2). However, besides the target product, large amounts of benzyl alcohol and benzoic acid resulting from base mediated Cannizzaro disproportionation of $\mathbf{1}$ accompanied by unidentified decomposition products of $\mathbf{2}$ were obtained. Unfortunately, neither addition of tetrabutylammonium bromide, ${ }^{16}$ nor reducing the reaction temperature improved suppression of these side reactions. Also using other

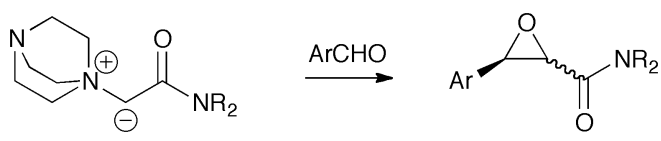

Scheme 1 Targeted use of amide-based ammonium ylides for epoxide formation. 
Table 1 Screening of conditions for the reaction of $\mathbf{1}$ and $\mathbf{2}$
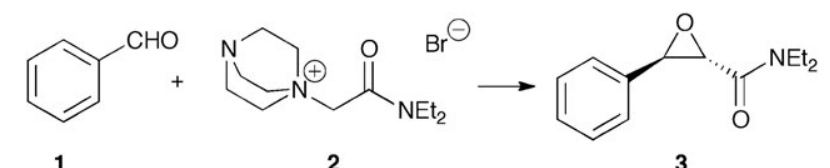

1

3

\begin{tabular}{|c|c|c|c|c|c|c|c|}
\hline Entry & Solvent & Base & $T\left({ }^{\circ} \mathrm{C}\right)$ & $t(\mathrm{~h})$ & $1: 2$ & $\begin{array}{l}\text { Yield }^{a} \\
(\%)\end{array}$ & $\begin{array}{l}\text { trans }^{b} \\
(\%)\end{array}$ \\
\hline 1 & $\mathrm{THF}$ & $t$-BuOK & $0 \rightarrow 25$ & 24 & 1.2 & 32 & $>99$ \\
\hline 2 & THF (4 ̊) & $t$-BuOK & $0 \rightarrow 25$ & 24 & 1.2 & 47 & $>99$ \\
\hline 3 & THF & $\mathrm{KOH}$ & $0 \rightarrow 25$ & 24 & 1.2 & 23 & $>99$ \\
\hline 4 & $\mathrm{EtOH}$ & $\mathrm{KOH}$ & $0 \rightarrow 25$ & 24 & 1.2 & 0 & $>99$ \\
\hline 5 & $\mathrm{CH}_{3} \mathrm{CN}$ & $\mathrm{Cs}_{2} \mathrm{CO}_{3}$ & $0 \rightarrow 25$ & 24 & 1.2 & 0 & $>99$ \\
\hline 6 & $\mathrm{CH}_{3} \mathrm{CN}(\mathrm{aq})$ & $\mathrm{KOH}$ & $0 \rightarrow 25$ & 24 & 1.2 & 0 & $>99$ \\
\hline 7 & DMSO & $t$-BuOK & $0 \rightarrow 25$ & 24 & 1.2 & 45 & $>99$ \\
\hline 8 & THF (4 A) & $t$-BuOK & $0 \rightarrow 25$ & 24 & 2 & 55 & $>99$ \\
\hline 9 & $\mathrm{CH}_{2} \mathrm{Cl}_{2}$ & $50 \% \mathrm{NaOH}$ & $0 \rightarrow 25$ & 24 & 1.2 & 55 & $>99$ \\
\hline 10 & $\mathrm{CH}_{2} \mathrm{Cl}_{2}$ & $50 \% \mathrm{NaOH}$ & $0 \rightarrow 25$ & 24 & 2 & 67 & $>99$ \\
\hline 11 & $\mathrm{CH}_{2} \mathrm{Cl}_{2}$ & $50 \% \mathrm{NaOH}$ & $0 \rightarrow 25$ & 24 & 3 & 77 & $>99$ \\
\hline 12 & $\mathrm{CH}_{2} \mathrm{Cl}_{2}$ & $50 \% \mathrm{NaOH}$ & $0 \rightarrow 25$ & 24 & 0.5 & 50 & $>99$ \\
\hline 13 & $\mathrm{CH}_{2} \mathrm{Cl}_{2}$ & $50 \% \mathrm{NaOH}$ & 40 & 8 & 3 & 76 & $>99$ \\
\hline 14 & $\mathrm{CH}_{2} \mathrm{Cl}_{2}$ & $50 \% \mathrm{KOH}$ & $0 \rightarrow 25$ & 24 & 3 & 62 & $>99$ \\
\hline
\end{tabular}

solvent/base combinations (entries $3-7$ in Table 1 give a representative overview of only a few of the tested conditions), no improvement could be achieved. Noteworthy, some of the conditions which were reported to be very successful in sulfur ylide transformations (e.g. entry 6$)^{17}$ gave absolutely no conversion in our case. The only significant product formation was observed when using $t$-BuOK in DMSO (45\%, entry 7$)$. As disproportionation of $\mathbf{1}$ was found to be the major limiting factor, 2 equiv. of aldehyde were used next (entry 8), but the yield could only be improved slightly (55\%), and large amounts of the Cannizzaro products were formed.

Accordingly, even with only equimolar amounts of base the disproportionation of the aldehyde limited the yield in all these homogeneous or liquid/solid experiments (entries 1-8). Therefore we investigated biphasic conditions in analogy to those reported by Jonczyk et al. ${ }^{11}$ Carrying out the reaction in a 2 : 1 mixture of $\mathrm{CH}_{2} \mathrm{Cl}_{2}$ and $50 \% \mathrm{NaOH}$ (aq) at ambient temperature $\left(25{ }^{\circ} \mathrm{C}\right)$, full conversion of $\mathbf{1}$ was observed within $24 \mathrm{~h}$. The oxirane 3 was obtained in 55\% yield with excellent trans-selectivity (entry 9). Although a big excess of base $(\sim 100$ equiv.) was necessary to achieve a reliable performance, the Cannizzaro reaction was well suppressed and only negligible amounts of benzyl alcohol could be detected. However, although all reactions were performed under inert conditions (Ar-atmosphere), considerable amounts of benzoic acid were formed presumably by autoxidation of $\mathbf{1}$. To overcome this limitation, the relative amount of $\mathbf{1}$ was doubled (entry 10). This increased the yield to $67 \%$ after a $24 \mathrm{~h}$ reaction time (longer reaction times did not improve the yield anymore). With 3 equiv. of 1 the yield was $77 \%$ (entry 11), while using an excess of ammonium salt $\mathbf{2}$, the yield dropped to $50 \%$ (entry 12). This clearly underscores that indeed the decomposition of $\mathbf{1}$ is the yield-limiting factor. Running the reaction at elevated temperature $\left(40{ }^{\circ} \mathrm{C}\right.$, with excess 1$)$ resulted in good conversion after $8 \mathrm{~h}$, giving 3 in $76 \%$ (entry 13). Noteworthy, carrying out the reaction at $40{ }^{\circ} \mathrm{C}$ for a longer
Table 2 Reaction of different amide derived ylides with 1

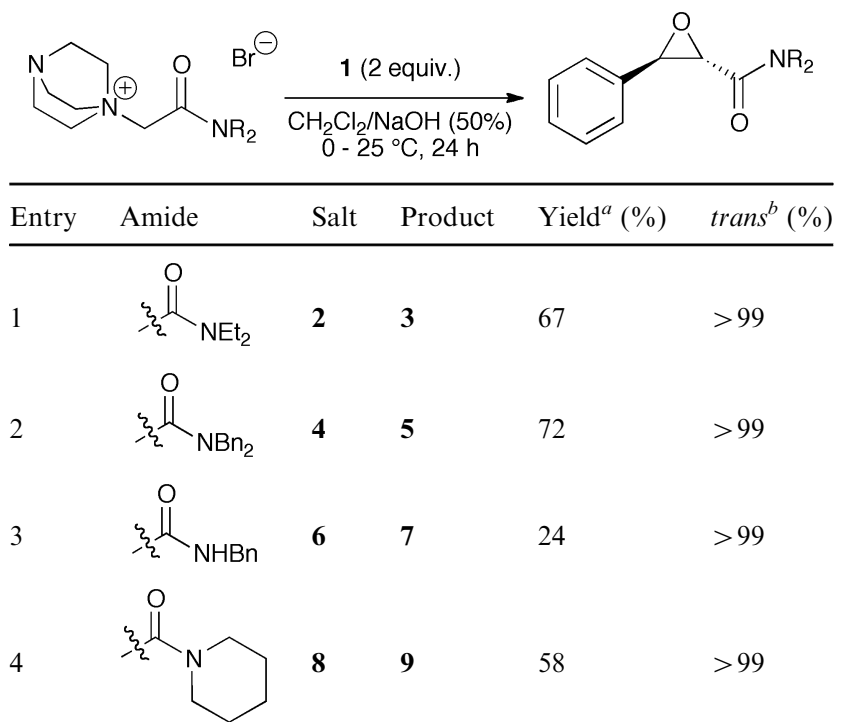

${ }^{a}$ Isolated yields. ${ }^{b}$ Determined by ${ }^{1} \mathrm{H}$ NMR of the crude product.

time $(>24 \mathrm{~h}$ ) resulted in a significant decomposition of the epoxide product. Using $50 \% \mathrm{KOH}(\mathrm{aq})$ as the base resulted in a reduced yield of $62 \%$ only (entry 14). Neither lower temperature, nor varying the amount of base or solvent ratios (e.g. less $\mathrm{H}_{2} \mathrm{O}$ ) and concentrations improved the yield any more.

Using quinuclidine-based ammonium salts instead of DABCO-derived ones gave 3 in 15\% yield only, whereas quinine as the amine part did not give any product, indicating the importance of leaving group ability for this reaction.

Having developed a reliable biphasic procedure for the highly trans-selective synthesis of $\mathbf{3}$ in a reasonable yield, we next investigated the use of other amide-derived ylides in the reaction with 1 ( 2 equiv.) ${ }^{18}$ under these conditions (Table 2).

It was clearly shown that all other amides give the products in high trans-selectivity too. Furthermore, other tertiary amides (entries 2 and 4, Table 2) give yields comparable to the test reaction between $\mathbf{1}$ and $\mathbf{2}$. However, using the secondary amide $\mathbf{6}$, the corresponding glycidic amide 7 could only be isolated in a reduced yield of $24 \%$ (entry 3 ). In this case, an increased amount of benzoic acid was obtained, due to autoxidation of unreacted 1. Accordingly, this lower yield is due to a significantly reduced reactivity of the secondary amide-derived salt $\mathbf{6}$ (a similar tendency for sulfur ylides was reported by Aggarwal et $a l^{4 b}$ ).

Finally, reaction of $\mathbf{2}$ with other aromatic aldehydes was investigated (Table 3). All reactions were first carried out under the standard conditions using 2 equiv. of the aldehyde (cond. A) to get a clear picture about the influence of the different substituents on the reactivity (entries 1-3, 5, 7, 9). All aldehydes reacted to the trans-epoxides exclusively. However, whereas the similarly activated aldehydes $\mathbf{1 0}$ and $\mathbf{1 2}$ gave the glycidic amides 11 and 13 in good yields (entries 2-4), the conversion of the more electron-rich anisaldehyde 14 was significantly lower resulting in a reduced yield of $47 \%$ after $24 \mathrm{~h}$. As expected, Cannizzaro reaction was no problem in this case but high amounts of unreacted $\mathbf{1 4}$ were found. The even 
Table 3 Reaction of different aromatic aldehydes with 2

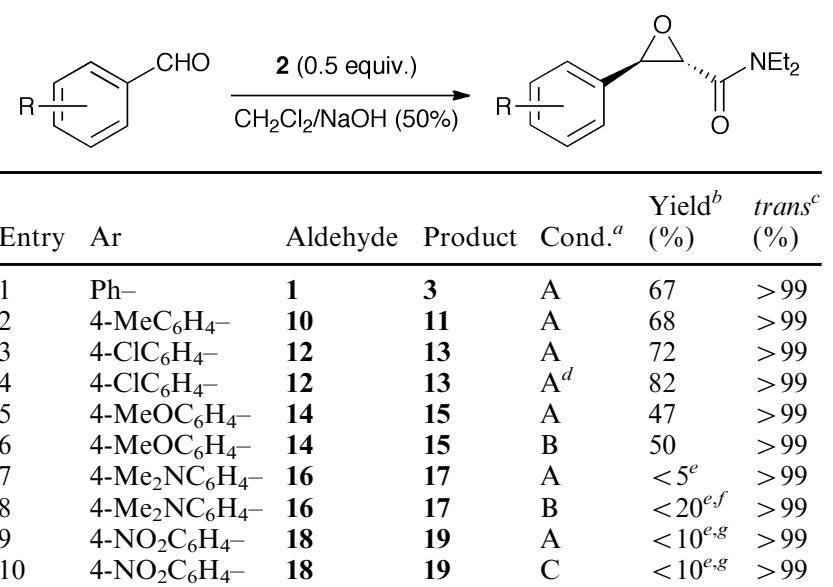

${ }^{a} \mathrm{~A}: 0 \rightarrow 25{ }^{\circ} \mathrm{C}, 24 \mathrm{~h}$; 100 equiv. $\mathrm{NaOH}$; B: $40{ }^{\circ} \mathrm{C}, 24 \mathrm{~h}, 100$ equiv. $\mathrm{NaOH}$; C: $0{ }^{\circ} \mathrm{C}, 24 \mathrm{~h}, 50$ equiv. $\mathrm{NaOH}^{b}$ Isolated yields. ${ }^{c}$ Determined by ${ }^{1} \mathrm{H}$ NMR of the crude product. ${ }^{d} 3$ equiv. of $\mathbf{1 2}$ were used. ${ }^{e}$ Judged by ${ }^{1} \mathrm{H}$ NMR of the crude product. ${ }^{f}$ The product decomposed during column chromatography. ${ }^{g}$ Complete Cannizzaro decomposition of $\mathbf{1 8 .}$

more electron rich dimethylaminobenzaldehyde $\mathbf{1 6}$ showed only minor conversion, giving just traces of product under standard conditions. By contrast, the highly electron-deficient nitrobenzaldehyde $\mathbf{1 8}$ was fully consumed within $24 \mathrm{~h}$, but giving mainly the corresponding Cannizzaro products and less than $10 \%$ of the product 19 even at reduced temperature and using less base (entries 9 and 10). Reaction of the deactivated 14 at elevated temperature $\left(40{ }^{\circ} \mathrm{C}\right.$, entry 6$)$ resulted in almost full conversion of $\mathbf{1 4}$ after $24 \mathrm{~h}$, giving $\mathbf{1 5}$ in $50 \%$ accompanied with unidentified by-products. This can be rationalized by decomposition of the aldehyde $\mathbf{1 4}$ as well as the oxirane $\mathbf{1 5}$ under these harsher basic conditions. On the other hand, even under these conditions, $\mathbf{1 6}$ was found to be rather unreactive yielding less than $20 \%$ of $\mathbf{1 7}$ (entry 8 ).

Accordingly, the aptitude of different aldehydes for this type of reaction strongly depends on their electronic properties. Whereas similarly activated aldehydes like 1, 10, and $\mathbf{1 2}$ give the glycidic amides in good yields, the electron poor $\mathbf{1 8}$ is prone to rapid Cannizzaro decomposition under the highly basic conditions. On the other hand, electron rich aldehydes like $\mathbf{1 4}$ and $\mathbf{1 6}$ are significantly less reactive.

In conclusion, although ammonium ylides bearing an $\alpha$-carbonyl group are less reactive in oxirane synthesis than sulfur ylides, excellent trans-selectivity and acceptable yields could be achieved by reacting amide-derived ammonium ylides with aromatic aldehydes. Key to success is the use of biphasic conditions together with a two-fold excess of aldehyde. The reaction is tolerant to different tertiary amide groups whereas secondary amides are less reactive. Using differently activated aldehydes, the outcome was strongly dependent on the electronic properties of the electrophile. Thus, it seems reasonable that this reaction is very close to the limit of what is possible with ammonium ylides. Nevertheless, to the best of our knowledge, this is the first time that stabilised ammonium ylides possessing an $\alpha$-carbonyl group have been successfully employed in oxirane formation.

This work was supported by the Austrian Science Funds (FWF) Project No. P22508-N17.

\section{Notes and references}

1 (a) E. J. Corey and M. Chaykovsky, J. Am. Chem. Soc., 1962, 84, 867; (b) E. J. Corey and M. Chaykovsky, J. Am. Chem. Soc., 1965, 87, 1353; (c) A. W. Johnson and R. B. Lacount, Chem. Ind., 1958, 1440

2 (a) V. K. Aggarwal, in Comprehensive Asymmetric Catalysis, ed. E. N. Jacobsen, A. Pfaltz and H. Yamamoto, Springer, New York, 1999, vol. 2, p. 679; (b) E. M. McGarrigle, E. L. Myers, O. Illa, M. A. Shaw, S. L. Riches and V. K. Aggarwal, Chem. Rev., 2007, 107, 5841.

3 (a) O. Illa, M. Arshad, A. Ros, E. M. McGarrigle and V. K. Aggarwal, J. Am. Chem. Soc., 2010, 132, 1828; (b) J. Zanardi, C. Leriverend, D. Aubert, K. Julienne and P. Metzner, J. Org. Chem., 2001, 66, 5620; (c) M. Davoust, J.-F. Briere, P.-A. Jaffres and P. Metzner, J. Org. Chem., 2005, 70, 4166 .

4 For syntheses of glycidic amides see: (a) Y.-G. Zhou, X.-L. Hou, L.-X. Dai, L.-J. Xia and M.-H. Tang, J. Chem. Soc., Perkin Trans. 1, 1999, 77; (b) V. K. Aggarwal, J. P. H. Charmant, D. Fuentes, J. N. Harvey, G. Hynd, D. Ohara, W. Picoul, R. Robiette, C. Smith, J.-L. Vasse and C. L. Winn, J. Am. Chem. Soc., 2006 , 128, 2105; (c) V. K. Aggarwal, G. Hynd, W. Picoul and J.-L. Vasse, J. Am. Chem. Soc., 2002, 124, 9964.

5 M. J. Porter and J. Skidmore, Chem. Commun., 2000, 1215.

6 For impressive examples see: (a) T. Nemoto, H. Kakei, V. Gnanadesikan, S.-Y. Tosaki, T. Ohshima and M. Shibasaki, J. Am. Chem. Soc., 2002, 124, 14544; (b) S. Matsunaga, T. Kinoshita, S. Okada, S. Harada and M. Shibasaki, J. Am. Chem. Soc., 2004, 126, 7559.

7 For two different stereoselective approaches see: (a) S. Arai, K. Tokumaru and T. Aoyama, Tetrahedron Lett., 2004, 45, 1845; (b) E. J. Corey and S. Choi, Tetrahedron Lett., 1991, 32, 2857.

8 (a) M. J. Gaunt and C. C. C. Johansson, Chem. Rev., 2007, 107, 5596; (b) C. C. C. Johansson, N. Bremeyer, S. V. Ley, D. R. Owen, S. C. Smith and M. J. Gaunt, Angew. Chem., Int. Ed., 2006, 45, 6024; (c) C. D. Papageorgiou, M. A. Cubillo de Dios, S. V. Ley and M. J. Gaunt, Angew. Chem., Int. Ed., 2004, 43, 4641; (d) N. Bremeyer, S. C. Smith, S. V. Ley and M. J. Gaunt, Angew. Chem., Int. Ed., 2004, 43, 2681; (e) C. D. Papageorgiou, S. V. Ley and M. J. Gaunt, Angew. Chem., Int. Ed., 2003, 42, 828.

9 (a) R. Robiette, M. Conza and V. K. Aggarwal, Org. Biomol. Chem., 2006, 4, 621; (b) V. K. Aggarwal, J. N. Harvey and R. Robiette, Angew. Chem., Int. Ed., 2005, 44, 5468.

10 C.-Y. Zhu, X.-M. Deng, X.-L. Sun, J.-C. Zheng and Y. Tang, Chem. Commun., 2008, 738.

11 For the use of cyano-stabilised ammonium ylides see: (a) A Kowalkowska, D. Sucholbiak and A. Jonczyk, Eur. J. Org. Chem., 2005, 925; (b) A. Jonczyk and A. Konarska, Synlett, 1999, 1085.

12 A. Alex, B. Larmanjat, J. Marrot, F. Couty and O. David, Chem. Commun., 2007, 2500.

13 For benzylic ammonium ylides see: T. Kimachi, H. Kinoshita, K. Kusaka, Y. Takeuchi, M. Aoe and M. Ju-ichi, Synlett, 2005, 842.

14 Y. Wang, Z. Chen, A. Mi and W. Hu, Chem. Commun., 2004, 2486.

15 An extensive study about ylide stability has recently been reported: Y. Fu, H.-J. Wang, S.-S. Chong, Q.-X. Guo and L. Liu, J. Org. Chem., 2009, 74, 810.

16 Ammonium additives might suppress Cannizzaro reactions: G. W. Gokel, H. M. Gerdes and N. W. Rebert, Tetrahedron Lett., 1976, 17, 653 .

17 K. Julienne and P. Metzner, J. Org. Chem., 1998, 63, 4532.

18 Using 2 equiv. of aldehyde represents a good compromise between required amount of starting materials and obtained yield. 